\title{
Comparative Analysis of Machining Characteristics of EDM and ECM during Machining of Ti-6Al-4V
}

\author{
D.O.I - 10.51201/Jusst12626 \\ http://doi.org/10.51201/Jusst12626
}

\author{
Sanjay $^{1}$, S.S.Banwait ${ }^{2}$ \\ ${ }^{1} P G$ Student, Department of Mechanical Engineering, National Institute of Technical Teachers Training \\ and Research (NITTTR), Chandigarh (India). \\ ${ }^{2}$ Professor, Department of Mechanical Engineering, National Institute of TechnicalTeachers \\ Training and Research (NITTTR), Chandigarh (India).
}

\begin{abstract}
The present work explains the machining of Titanium alloy using Electric Discharge Machining \& Electro-Chemical Machining. This work aims to analyze the role of Current, Pulse on Time, Voltage and hence optimize the Material Removal Rate and Surface Roughness in Electric Discharge Machining. In the same way, it also aims to analyze the role of Concentration, Feed, and Voltage and optimize the Material Removal Rate and Surface Roughness in Electro-Chemical Machining. The various approaches like Taguchi \& Analysis of Variance are executed to study the performance characteristics of the input parameters on the output parameters. The whole work is followed by a validation test and hence confirming the obtained values. Thus, it reveals the acceptability of the model. The work tells that Material Removal Rate and Surface Finish effect is more in Electro-Chemical Machining as compared to Electric Discharge Machining. For Material Removal Rate, Current and Feed are more responsible parameters for Electric Discharge Machining. In the same way; electrolyte concentration and Feed are more responsible parameters for Electro-Chemical Machining respectively.
\end{abstract}

Keywords:Titanium, EDM, ECM, Taguchi, ANOVA.

\section{INTRODUCTION}

The alpha-beta alloys, Ti-6Al-4V are by far the most popular titanium alloy. More than $50 \%$ of all alloys in use today are of this composition. Grade 5 (Ti-6Al-4V) titanium alloy is an alpha-beta alloy that can be heat treated to higher strength and heavier section size. Titanium alloy possesses excellent strength, good corrosion resistance, and medium fabricability.

G. Kibria et al. [1] studied the effect of different types of dielectrics to find out its effects on the machining outputs such as material removal rate (MRR), tool wear rate (TWR), overcut, diametral variance at entry and exit hole, and surface integrity using EDM and ECM. Shailendra Kumar Singh et al. Han-Ming Chow et al. [2] experimented by using two types of powders such as SiC and Al powder in kerosene oil for investigating their effects on the machining output such as material removal rate (MRR), tool wear rate (TWR), surface roughness, and the slit expansion. M. Ali Okay et al. [3] conducted a set of EDM fast hole drilling operations to explore the effect of single and multi-channel tubular electrodes on material removal rate, electrode wear, and microhardness. Lei Li et al. [4] studied the effect of a bundled electrode on machining output. Different input parameters such as peak current, fluid flow rate, pulse on-time, and pulse- off time were selected to investigate their effects on material removal rate (MRR), tool wear rate (TWR). Ulas Caydas et al. [5] have carried out a study to optimize the process parameters by applying different types of electrode materials. Khalid Hussain Syed et al. [6] tries to optimize the process parameters so that maximum MRR, low EWR, higher surface finish, and minimum white layer thickness can be achieved. K. K. Singh et al. [7] investigated the effect of chromium powder on material removal rate, electrode wear rate, surface roughness, and white layer thickness. 
Meena Laad et al. [8] investigated the enhancement in surface properties of Ti- 6Al-4V alloy machined by EDM process by using graphite electrode. Gap current, pulse on time, and pulse off time were taken as EDM process parameters and micro-hardness was taken as the response output. B. Bhattacharyya et.al[9] Investigated controlled ECM through response surfacemethodology utilizing the relevant experimental data as obtained through experimentation. The analysis of the experimental observations highlighted that the MRR in ECM is greatly influenced by the various dominant process parameters such as electrolyte concentration, electrolyte flow rate applied voltage inter-electrode gap considered in the study. R V Rao et.al [10]studied that the selection of critical process parameters of ECM methods suchas feed rate, the flow velocity of electrolyte, and voltage plays an important role in improving the measures of process performance. These incorporate dimensional accuracies, MRR, machining cost, and tool life. A particle optimization algorithm is exhibited to locate the optimal combination of process parameters for the ECM process.

In the sum of the above analysis, it has been found that limited literature is available Comparative study of EDM and ECM of titanium alloy. the workpiece material and tool material are same used in ECM and EDM. but ECM and EDM different input parameters are suedes input parameters are used electrolyte concentration, feed rate, and voltage. EDM input parameters are used current, pulse on time, and voltage. The machining time is constant for both EDM and ECM processes.

\section{MATERIAL \& METHODS}

Titanium alloy (Ti-6Al-4V, Grade 5) is used as workpiece material.The chemical composition of titanium Ti-6Al-4V alloyis titanium $90 \%$, aluminum $6 \%$, iron $0.25 \%$ maximum, oxygen $0.2 \%$ maximum and vanadium $4 \%$.

Copper is used as an electrode tool material for machining titanium alloy material for EDM and ECM processes. The copper tool diameter is $18 \mathrm{~mm}$ and the tool shape is circular for both EDM and ECM processes. copper is a ductile metal. It should be electrically conductive and low electrical resistance.

Taguchi Method is used for an experiment for this process. The Design of Experiments chosen for the ECM and EDM of Titanium alloy (Ti-6Al-4V) was a Taguchi L9 orthogonal array, consisting of a total number of 9 trial of experiments.

Table 1Taguchi L9 Design

\begin{tabular}{|c|c|c|}
\hline Current & Pulse & Voltage \\
\hline 1 & 1 & 1 \\
\hline 1 & 2 & 2 \\
\hline 1 & 3 & 3 \\
\hline 2 & 1 & 2 \\
\hline 2 & 2 & 3 \\
\hline 2 & 3 & 1 \\
\hline 3 & 1 & 3 \\
\hline 3 & 2 & 1 \\
\hline 3 & 3 & 2 \\
\hline
\end{tabular}


Table 2 Experimental Data

\begin{tabular}{|c|c|c|c|c|c|c|}
\hline $\begin{array}{c}\text { current } \\
(\mathbf{I})\end{array}$ & $\begin{array}{c}\text { Pulse } \\
\text { on time } \\
\text { (Ton) }\end{array}$ & Voltage(V) & MRR(g/min) & Ra( $\mathbf{\mu m})$ & SNRA1 & SNRA2 \\
\hline 11 & 99 & 38 & 0.0219 & 2.21 & -33.1911 & -6.88785 \\
\hline 11 & 149 & 48 & 0.023 & 3.68 & -32.7654 & -11.317 \\
\hline 11 & 199 & 58 & 0.0255 & 4.48 & -31.8692 & -13.0256 \\
\hline 15 & 99 & 48 & 0.0272 & 5.68 & -31.3086 & -15.087 \\
\hline 15 & 149 & 58 & 0.0346 & 4.46 & -29.2185 & -12.9867 \\
\hline 15 & 199 & 38 & 0.0311 & 5.12 & -30.1448 & -14.1854 \\
\hline 17 & 99 & 58 & 0.045 & 2.8 & -26.9357 & -8.94316 \\
\hline 17 & 149 & 38 & 0.0562 & 5.64 & -25.0053 & -15.0256 \\
\hline 17 & 199 & 48 & 0.0546 & 6.44 & -25.2561 & -16.1777 \\
\hline
\end{tabular}

Analysis of input factors that affect the MRR and surface roughness of Titanium alloy in ECM is described Below.

The Response table for the signal to noise ratios MRR is shown in table 3 and the corresponding ANOVA Table is shown in Table 4.MRR, the calculation of $\mathrm{S} / \mathrm{N}$ ratio follows larger is a better model.

Table.3 Response table for the signal to noise ratios MRR

\begin{tabular}{|l|l|l|l|}
\hline Level & Current $(\mathrm{I})$ & $\begin{array}{l}\text { Pulse on time } \\
\left(\mathrm{T}_{\text {on }}\right)\end{array}$ & Voltage $(\mathrm{V})$ \\
\hline 1 & -32.61 & -30.48 & -29.45 \\
\hline 2 & -30.22 & -29.00 & -29.78 \\
\hline 3 & -25.73 & -29.09 & -29.34 \\
\hline Delta & 6.88 & 1.48 & 0.44 \\
\hline Rank & 1 & 2 & 3 \\
\hline
\end{tabular}

Table 3 specified the average effect response tables for obtained data and S/N ratio, these tables help us find out which parameters will affect more significantly. As shown in table 3 maximum and minimum difference peak current, pulse on time, and applied voltage are ranked 1,2,3, respectively. so it is concluded that the peak current has a major effect on MRR quality than pulse on time and voltage.

A general linear model of ANOVA was used to conduct an ANOVA test which requires a response and the factors affecting the response. Table 4 results of the analysis of variance for MRR for S/N data which specify signal of different parameters on the MRR are summarized as below. 
Table 4 ANOVA for MRR

\begin{tabular}{|l|l|l|l|l|l|l|l|}
\hline Source & D.O.F & SS & Contribution & Adj SS & A Dj MS & F-Value & P-Value \\
\hline Current & 2 & 0.001306 & $92.39 \%$ & 0.001306 & 0.000653 & 48.01 & 0.020 \\
\hline Pulse on time & 2 & 0.000076 & $5.40 \%$ & 0.000076 & 0.000038 & 2.81 & 0.263 \\
\hline Voltage & 2 & 0.000004 & $0.28 \%$ & 0.000004 & 0.000002 & 0.15 & 0.871 \\
\hline Error & 2 & 0.000027 & $1.92 \%$ & 0.000027 & 0.000014 & & \\
\hline Total & 8 & 0.001414 & $100.00 \%$ & & & & \\
\hline
\end{tabular}

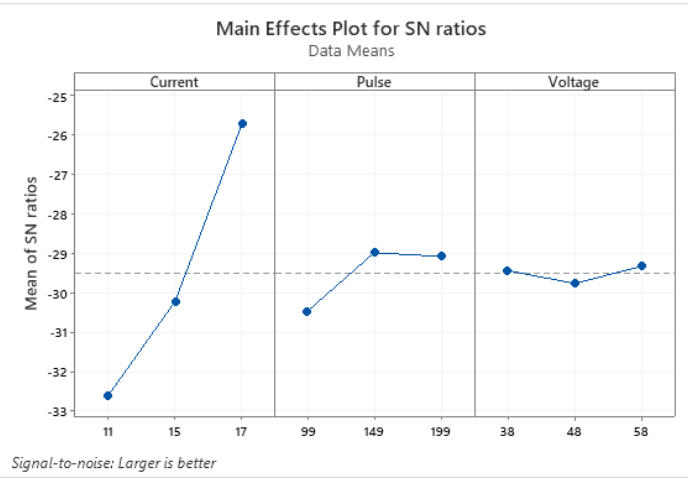

Figure 2. S/N Ratio Curve For MRR

As seen in the response and $\mathrm{S} / \mathrm{N}$ ratio effect graph, peak current has a strong effect on MRR and their $\mathrm{S} / \mathrm{N}$ ratio. The pulse on-time and voltage have a smaller effect, which is evident from the shallow slope of the lines. the graph indicates the levels at which the S/N ratio and MRR effect are at their optimal magnitude; that is, their $\mathrm{S} / \mathrm{N}$ ratio effect is at its highest magnitude and the MRR effect is at its largest magnitude. From fig.2.MRR increases when pulse on time is increased.

The Response table for the signal to noise ratios Surface Roughness is shown in table 5 and the corresponding ANOVA Table is shown in Table 6. Surface Roughness, the calculation of S/N ratio follows smaller is a better model.

Table 5 Response table for the signal to noise ratios Surface Roughness

\begin{tabular}{|l|l|l|l|}
\hline Level & Current & Pulse on Time & Voltage \\
\hline 1 & -10.41 & -10.31 & -12.03 \\
\hline 2 & -14.09 & -13.11 & -14.19 \\
\hline 3 & -13.38 & -14.46 & -11.65 \\
\hline Delta & 3.68 & 4.16 & 2.54 \\
\hline Rank & 2 & 1 & 3 \\
\hline
\end{tabular}

Table 5 specified the average effect response tables for obtained data and $\mathrm{S} / \mathrm{N}$ ratio, these tables help us find out which parameters will affect more significantly. As shown in table 5 maximum and minimum 
difference peak current, pulse on time, and applied voltage are ranked 1,2,3, respectively. so it is concluded that the peak current has a major effect on surface quality than pulse on time and voltage.

A general linear model of ANOVA was used to conduct an ANOVA test which requires a response and the factors affecting the response. Table 6 results of the analysis of variance for surface roughness for $\mathrm{S} / \mathrm{N}$ data which specify signal of different parameters on the surface roughness are summarized as below.

Table 6 ANOVA for Surface Roughness

\begin{tabular}{|l|l|l|l|l|l|l|l|}
\hline Source & D.O.F & SS & Contribution & Adj SS & Adj MS & F-Value & P-Value \\
\hline Current & 2 & 4.933 & $31.52 \%$ & 4.933 & 2.466 & 1.63 & 0.380 \\
\hline $\begin{array}{l}\text { Pulse on } \\
\text { time }\end{array}$ & 2 & 4.809 & $30.73 \%$ & 4.809 & 2.404 & 1.59 & 0.386 \\
\hline Voltage & 2 & 2.889 & $18.46 \%$ & 2.889 & 1.445 & 0.96 & 0.511 \\
\hline Error & 2 & 3.017 & $19.28 \%$ & 3.017 & 1.509 & & \\
\hline Total & 8 & 15.648 & $100.00 \%$ & & & & \\
\hline
\end{tabular}

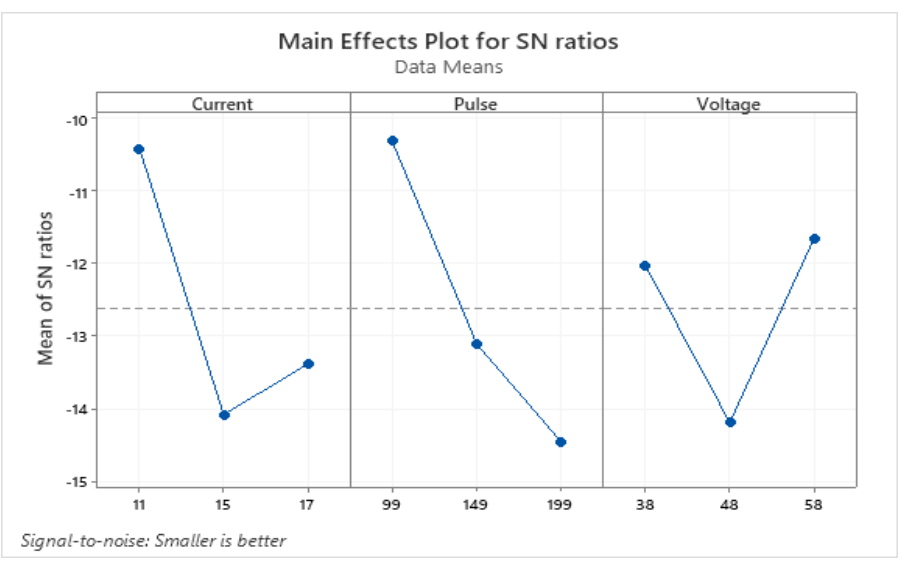

Figure 3. S/N Ratio Curve for Surface Roughness

As seen in the response and $\mathrm{S} / \mathrm{N}$ ratio effect graph, pulse on time has a strong effect on surface roughness and their $\mathrm{S} / \mathrm{N}$ ratio. The peak current and voltage have a smaller effect, which is evident from the shallow slope of the lines. the graph indicates the levels at which the $\mathrm{S} / \mathrm{N}$ ratio and surface roughness effect are at their optimal magnitude; that is, their $\mathrm{S} / \mathrm{N}$ ratio effect is at its highest magnitude and the surface roughness effect is at its smallest magnitude. From fig. 3 surface roughness increases when pulse on time is increased.

Table 7 Results of confirmation test for MRR and surface roughness in EDM

\begin{tabular}{|c|c|c|c|}
\hline Response parameter & Experimental value & Predicated value & Error\% \\
\hline MRR & 0.0562 & 0.0577 & 2.67 \\
\hline Surface roughness & 2.21 & 2.13 & 3.76 \\
\hline
\end{tabular}

The error between Predicted MRR \& Experimental MRR is $2.67 \%$ i.e., below 5\%. Thus, the work is validated. In the same way, the error between Predicted Ra \& Experimental Ra is $3.76 \%$ i.e., below 5 $\%$. Hence, the work is validated \& acceptable. Analysis of input factors that affect the MRR and surface roughness of Titanium alloy in ECM is described below. 
Table 8 Experimental Data

\begin{tabular}{|c|c|c|c|c|c|c|}
\hline Concentration & Feed & Voltage & MRR & Ra & SNRA1 & SNRA2 \\
\hline$(\mathrm{g} / \mathrm{ltr})$ & $(\mathrm{mm} / \mathrm{min}) \times 10^{-3}$ & $(\mathrm{v})$ & $(\mathrm{g} / \mathrm{min})$ & $\mu \mathrm{m}$ & & \\
\hline 150 & 144 & 15 & 0.136 & 6.4 & -17.3292 & -16.1236 \\
\hline 150 & 180 & 20 & 0.033 & 1.93 & -29.6297 & -5.71115 \\
\hline 150 & 240 & 25 & 0.096 & 0.71 & -20.3546 & 2.974833 \\
\hline 200 & 144 & 20 & 0.153 & 7.3 & -16.3062 & -17.2665 \\
\hline 200 & 180 & 25 & 0.077 & 1.94 & -22.2702 & -5.75603 \\
\hline 200 & 240 & 15 & 0.098 & 0.92 & -20.1755 & 0.724243 \\
\hline 250 & 144 & 25 & 0.145 & 11.52 & -16.7726 & -21.229 \\
\hline 250 & 180 & 15 & 0.078 & 2.27 & -22.1581 & -7.12052 \\
\hline 250 & 240 & 20 & 0.161 & 6.67 & -15.8635 & -16.4825 \\
\hline
\end{tabular}

The Response table for the signal to noise ratios MRR is shown in table 9 and the corresponding ANOVA Table is shown in Table 10 MRR, the calculation of $\mathrm{S} / \mathrm{N}$ ratio follows larger is a better model.

Table 9 Response table for the signal to noise ratios

\begin{tabular}{|c|c|c|c|}
\hline Level & Concentration & Feed rate & Voltage \\
\hline 1 & -22.44 & -16.80 & -19.89 \\
\hline 2 & -19.58 & -24.69 & -20.60 \\
\hline 3 & -18.26 & -18.80 & -19.80 \\
\hline Delta & 4.17 & 7.88 & 0.80 \\
\hline Rank & 2 & 1 & 3 \\
\hline
\end{tabular}

Table 9 specified the average effect response tables for obtained data and $\mathrm{S} / \mathrm{N}$ ratio, these tables help us find out which parameters will affect more significantly. As shown in table 9 maximum and minimum difference electrolyte concentration, feed rate, and applied voltage are ranked 1,2,3, respectively. so it is concluded that the electrolyte concentration has a major effect on MRR quality than feed rate and voltage.

A general linear model of ANOVA was used to conduct an ANOVA test which requires a response and the factors affecting the response. Table 10 results of the analysis of variance for MRR for $\mathrm{S} / \mathrm{N}$ data which specify signal of different parameters on the MRR are summarized as below.

Table 10 ANOVA for MRR

\begin{tabular}{|c|c|c|c|c|c|}
\hline Source & D.O.F & A & A & F-V & P-V \\
\hline Concentration & 2 & 0.002363 & 0.001181 & 1.48 & 0.404 \\
\hline Feed rate & 2 & 0.010516 & 0.005258 & 6.57 & 0.132 \\
\hline Voltage & 2 & 0.000234 & 0.000117 & 0.15 & 0.873 \\
\hline Error & 2 & 0.001602 & 0.000801 & & \\
\hline Total & 8 & 0.014714 & & & \\
\hline
\end{tabular}




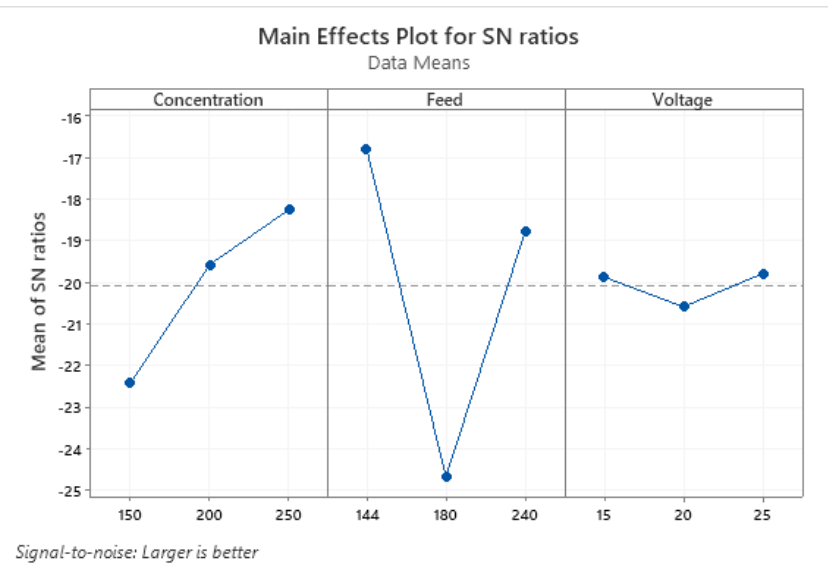

Figure. 3 S/N Ratio Curve For MRR

As seen in the response and $\mathrm{S} / \mathrm{N}$ ratio effect graph, electrolyte concentration has a strong effect on MRR and their $\mathrm{S} / \mathrm{N}$ ratio. The feed rate and voltage have a smaller effect, which is evident from the shallow slope of the lines. the graph indicates the levels at which the S/N ratio and MRR effect are at their optimal magnitude; that is, their $\mathrm{S} / \mathrm{N}$ ratio effect is at its highest magnitude and the MRR effect is at its largest magnitude. From fig.4 MRR increases when electrolyte concentration is increased.

The Response table for the signal to noise ratios Surface Roughness is shown in table 11 and the corresponding ANOVA Table is shown in Table 12 Surface Roughness, the calculation of S/N ratio follows smaller is a better model.

Table 11 Response table for the signal to noise ratios

\begin{tabular}{|c|c|c|c|}
\hline Level & concentration & Feed rate & Voltage \\
\hline 1 & -6.287 & -18.206 & -7.507 \\
\hline 2 & -7.433 & -6.196 & -13.153 \\
\hline 3 & -14.944 & -4.261 & -8.003 \\
\hline Delta & 8.657 & 13.945 & 5.647 \\
\hline Rank & 2 & 1 & 3 \\
\hline
\end{tabular}

Table 11 specified the average effect response tables for obtained data and $\mathrm{S} / \mathrm{N}$ ratio, these tables help us find out which parameters will affect more significantly. As shown in table 11 maximum and minimum difference electrolyte concentration, feed rate, and applied voltage are ranked 1,2,3, respectively. so it is concluded that the electrolyte concentration has a major effect on surface quality than feed rate and voltage.

A general linear model of ANOVA was used to conduct an ANOVA test which requires a response and the factors affecting the response. Table 12 results of the analysis of variance for surface roughness for $\mathrm{S} / \mathrm{N}$ data which specify signal of different parameters on the surface roughness are summarized as below. 
Table 12 ANOVA for Surface Roughness

\begin{tabular}{|c|c|c|c|c|c|}
\hline Source & D.O.F & Adj SS & Adj MS & F-Value & P-Value \\
\hline Concentration & 2 & 26.418 & 13.209 & 6.02 & 0.142 \\
\hline Feed rate & 2 & 72.778 & 36.389 & 16.58 & 0.057 \\
\hline Voltage & 2 & 7.087 & 3.544 & 1.61 & 0.382 \\
\hline Error & 2 & 4.390 & 2.195 & & \\
\hline Total & 8 & 110.673 & & & \\
\hline
\end{tabular}

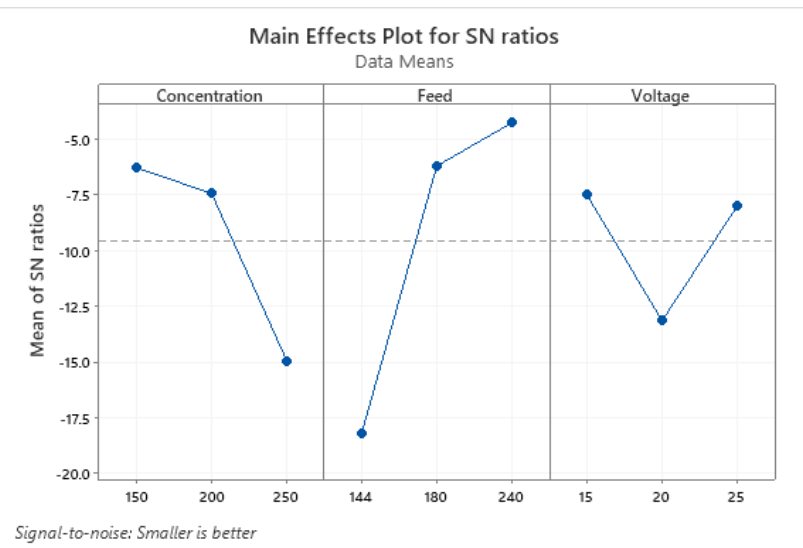

Figure4 S/N Ratio Curve For surface roughness

As seen in the response and $\mathrm{S} / \mathrm{N}$ ratio effect graph, electrolyte concentration has a strong effect on surface roughness and their $\mathrm{S} / \mathrm{N}$ ratio. The feed rate and voltage have a smaller effect, which is evident from the shallow slope of the lines. the graph indicates the levels at which the $\mathrm{S} / \mathrm{N}$ ratio and surface roughness effect are at their optimal magnitude; that is, their $\mathrm{S} / \mathrm{N}$ ratio effect is at its highest magnitude and the surface roughness effect is at its smallest magnitude. From fig.5.surface roughness increases when electrolyte concentration is increased.

Table 13 Results of confirmation test for MRR and surface roughness in ECM

\begin{tabular}{|c|c|c|c|}
\hline Response parameter & Experimental value & Predicated value & Error\% \\
\hline MRR & 0.161 & 0.164 & $1.86 \%$ \\
\hline Surface roughness & 0.71 & 0.70 & $1.41 \%$ \\
\hline
\end{tabular}

The error between Predicted MRR \& Experimental MRR is $1.86 \%$ i.e., below 5\%. Thus, the work is validated. In the same way, the error between Predicted Ra \& Experimental Ra is $1.41 \%$ i.e., below 5 $\%$. Hence, the work is validated $\&$ acceptable.

Economic analysis, considering the Material cost, Tool cost, Dielectric fluid, Power consumption and Machining cost. 
Table 14 Economic analysis for both EDM and ECM

\begin{tabular}{|l|l|l|l|}
\hline $\begin{array}{l}\text { Sr. } \\
\text { No. }\end{array}$ & Cost & EDM & ECM \\
\hline 1 & Workpiece cost & 1399.50 & 1399.50 \\
\hline 2 & Tool cost & 250 & 250 \\
\hline 3 & Dielectric fluid/electrolyte cost & 115 & 1800 \\
\hline 4 & Power consumption & 50 & 50 \\
\hline 5 & Total Machining cost & 1814.50 & 3499.50 \\
\hline
\end{tabular}

Economic analysis for both EDM and ECM, the workpiece material cost is the same, and tool cost is the same. The machining cost, ECM is more costly as comparison of EDM, because of electrolyte iscostly. Thetwo or more $\left(\mathrm{NaCl}, \mathrm{NaNO}_{3}\right)$ type of electrolyte are used and in the case of EDM,EDM-oil is used as dielectric fluid. EDM oil cost is less in comparison to ECM electrolytic is a more time-consuming process as compare to EDM Because different electrolytes are used.

\section{RESULTS AND DISCUSSION}

As MRR is more in the case of ECM as compared to EDM. Thus, we can say that ECM helps in more machining of Titanium as compared with EDM. Also, the surface roughness of Titanium with the machining of ECM is less as compared to EDM. Thus, ECM provides better surface finishing to Titanium during machining. Overall, we can say that ECM plays a better role in providing good machining \& a better surface finishing to titanium.

\section{CONCLUSION}

The optimum input parameters for high MRR in EDM in titanium alloy obtained were $0.0562 \mathrm{~mm} / \mathrm{min}$, peak current is $17 \mathrm{~A}$, pulse on time is $149 \mu \mathrm{sec}$, applied voltage is $38 \mathrm{v}$. The experimental value of MRR obtained is $0.0562 \mathrm{~mm} / \mathrm{min}$.and the predicted value is $0.0577 \mathrm{~mm} / \mathrm{min}$. The percentage error is $2.67 \%$ which is well with the permissible limit.

The optimum input parameters for low surface roughness in EDM in titanium alloy obtained were 2.21 $\mu \mathrm{m}$, peak current is $11 \mathrm{~A}$, pulse on time is $99 \mu \mathrm{sec}$, the applied voltage is $38 \mathrm{v}$. The experimental value of surface roughness obtained is $2.21 \mu \mathrm{m}$.and the predicted value is $2.13 \mu \mathrm{m}$. the percentage error is $3.76 \%$ which is well with the permissible limit.

The optimum input parameters for high MRR in ECM in titanium alloy obtained were $0.161 \mathrm{~mm} / \mathrm{min}$, electrolyte concentration is $250 \mathrm{~g} / \mathrm{ltr}$, the feed rate is $240 \mathrm{~mm} / \mathrm{min}$, the applied voltage is $20 \mathrm{v}$. The experimental value of MRR obtained is $0.161 \mathrm{~mm} / \mathrm{min}$. and the predicted value is $0.164 \mathrm{~mm} / \mathrm{min}$. The percentage error is $1.86 \%$ which is well with the permissible limit.

The optimum input parameters for low surface roughness in ECM in titanium alloy obtained were 0.71 $\mu \mathrm{m}$, electrolyte concentration is $150 \mathrm{~g} / \mathrm{ltr}$, the feed rate is $240 \mathrm{~mm} / \mathrm{min}$, the applied voltage is $25 \mathrm{v}$. The experimental value of surface roughness obtained is $0.71 \mu \mathrm{m}$.and the predicted value is $0.70 \mu \mathrm{m}$. the percentage error is $1.41 \%$ which is well with the permissible limit. 


\section{Acknowledgment}

This experimental work is supported by the National Institute of Technical Teachers' Training and Research (NITTTR), Chandigarh (India).

\section{References}

[1] Kibria G., Sarkar B. R., Pradhan B. B., LinY C. and, Lee H., and Bhattacharyya B. " "Comparative study of different dielectrics for micro-EDM performance during micro-hole machining of Ti-6Al-4V alloy", Int J Adv Manuf Technology (2010) 48:557-570.

[2] Chow H M., Yan B H., Huang F Y and Hung J C., "Study of added powder in kerosene for the microslit machining of titanium alloy using electro-discharge machining", Journal of Materials Processing Technology 101 (2000), pp.95-103.

[3] Yilmaz O. and Okka M.A. "Effect of single and multi-channel electrodes application on EDM fast hole drilling performance", International Journal of Advanced Manufacturing Technology 51 (2010)185-194.

[4] Gu L., Li L., Zhao $W$ and Rajurkar K.P "Electrical discharge machining of Ti- 6Al-4V with a bundled electrode" International Journal of Machine Tools \& Manufacture 53 (2012)100-106.

[5] Hascalik A. and Caydas U., "Electrical discharge machining of titanium alloy (Ti-6Al-4V)", Applied Surface Science 253 (2007)9007-9016.

[6] Syed K H. and, Kuppan Palaniyandi K., "Performance of electrical discharge machining using aluminum powder suspended distilled water", Turkish J. Eng. Env. Sci. 36 (2012), pp.195-207.

[7] Ojha K., Garg R K. and Singh K K., "MRR Improvement in Sinking Electrical Discharge Machining: A Review", Journal of Minerals \& Materials Characterization and Engineering, Vol. 9, No.8, (2010)pp.709739.

[8] Laad M., Jatti V K S., and Jadhav P P., "Investigation into the application of electrical discharge machining as a surface treatment process" Wseas transactions on applied and theoretical mechanics, Vol. 9, (2014),pp.245-251.

[9] B. Bhattacharyya and S. K. Sorkhel, "Investigation for controlled electrochemical machining through response surface methodology-based approach," J. Mater. Process. Technol., vol. 86, no. 1-3, 1998, pp. 200-207.

[10] R. V. Rao, P. J. Pawar, and R. Shankar, "Multi-objective optimization of electrochemical machining process parameters using a particle swarm optimization algorithm," Proc. Inst. Mech. Eng. Part B J. Eng. Manuf., vol. 222, no. 8,2008, pp. 949-958. 